\title{
DEA Window Analysis for Measuring Port Performances Efficiency of Four Islands Countries Located in West Indian Ocean Countries
}

\author{
Onally Dewarlo \\ College of Transport \& Communications, Shanghai Maritime University, Shanghai, China \\ Email: 15957155013@163.com
}

How to cite this paper: Dewarlo, O. (2019) DEA Window Analysis for Measuring Port Performances Efficiency of Four Islands Countries Located in West Indian Ocean Countries. American Journal of Industrial and Business Management, 9, 2098-2111. https://doi.org/10.4236/ajibm.2019.912139

Received: October 23, 2019

Accepted: December 3, 2019

Published: December 6, 2019

Copyright $\odot 2019$ by author(s) and Scientific Research Publishing Inc. This work is licensed under the Creative Commons Attribution International License (CC BY 4.0).

http://creativecommons.org/licenses/by/4.0/

\begin{abstract}
DEA window analysis has been a great tool used in improving the economic impacts of ports through its efficiency analysis. This has been employed to ports found in West Africa, Europe, Asia ports; nonetheless, this has not been applied to Indian Ocean Island ports. The purpose of this paper is to investigate the port efficiencies of four island port countries found in the West Indian Ocean (port Reunion, the port of Colombo, Port Louis and the port of Toamasina). DEA window analysis is used to determine port efficiency and to observe the possibility of changes in port efficiency over time. Despite the measures were put in place to improve the efficiency of the port, corruption, unskilled labour and others are some inefficiencies that hinder the performance of the port. Implications and future research directions are also included in this study.
\end{abstract}

\section{Keywords}

DEA Analysis, Port Efficiency, Western Indian Ocean, Window Analysis, Indian Ocean Island Countries, Efficiency, Performance

\section{Introduction}

\subsection{Background}

The Indian Ocean is fast becoming the new centre of economic gravity, as it ties together the economic fortunes of emerging Asia, the US, and Europe. Maritime rivalries in the Indian Ocean are an early indicator of the return of great-power economics of the country that profits this great opportunity. The place of the In- 
dian Ocean in the world economy becomes predominant with the rise of South Asia and India. Its strategic sensitivity appears every day more. Bordered by the world's largest hydrocarbon reserve, the southern Indian Ocean area serves as a vehicle for marine oil transport. 50\% of this transport is transported each year from the Persian Gulf to Cape Town via the Mozambique canal. The container roads also cross it to Asia that is Malacca-Suez and Malacca-Le Cap, vital for world trade. There are several Islands in the Indian Ocean who could benefit from maritime transport, like Sri Lanka, Mauritius, Reunion Island and Madagascar. Found in the south-west of the Indian Ocean, Reunion and Mauritius form the Mascarene archipelago. Both are $200 \mathrm{~km}$ apart. If Reunion is a French overseas department, Mauritius, a former British possession, is independent since 1968, they have a good port located in the west part of Indian Ocean. While the island of Madagascar is also on the edge of the Indian Ocean, it is surrounded by $5,000 \mathrm{~km}$ of coast, the southeast coast of Africa. It is estimated that most of its international trade $(+90 \%)$ is made via the port of Toamasina and also via the main regional and worldwide shipping routes. Moreover, Sri Lanka, whose geographical positioning is very strategic, is located at the southern tip of the only continental mass extending to the Indian Ocean between Arab and Malay peninsulas. Their strategic position naturally gives Sri Lanka an additional competitive advantage to develop as an Asian maritime centre. The development of the port of Colombo as the central port hub of the region in the 19th and 20th centuries was also greatly facilitated by this competitive advantage of strategic positioning.

\subsection{Research Objectives}

Maritime transport is a global economy that accounts for $90 \%$ of the total volume of world trade. The Merchant Navy plays an essential role in the realization of commercial transactions between the different continents of the world, whether it is raw materials, food products or manufactured goods.

Maritime transport is one of the cheapest means of transport, all types, both in terms of cost of materials and capacity. It has many features that do not require continuous modifications, except at the beginning and end for the port's roads and docks.

Due to the importance of Shipping and its additional benefits, it is considered to be the backbone of the country's economy and the basis for sustainable development. Thus, without the different means of transport, in particular, maritime transport, investment opportunities and business conditions will be negatively affected by some other countries.

This paper, therefore, aims to examine the performance efficiency of following strategic seaports in West of the Indian Ocean, the port of Reunion, the port of Colombo, the Port Louis Port and the port of Toamasina. These islands in the west of the Indian Ocean are strategic in the sense that they are counted among the key to transport maritime in the Indian Ocean, added to the fact that they compete for the same markets. So after the examination of the performance effi- 
ciency for those four Island port, we need to answer this following key question:

1) Which Port is the most efficient among them four?

2) What is the main reason for inefficiency of the other port?

3) What are the solutions we should suggest about those inefficiency problems?

The remainder of this study is organized in the following way. Section 1 presents the introduction, the research question and the theoretical research basis on the topic of ports performance efficiency and DEA. Section 2 introduces the methodology adopted; then Section 3 presents the data source and discusses the empirical results of the four studied strategic island ports in the west of the Indian Ocean. The paper concludes the study in Section 4.

\subsection{Literature Review}

The term "performance" is generally understood as an industrial word to assess the success of an organization in achieving a certain level of its strategic objectives [1]. Logistic performance can be defined as the degree of achievement of a company's objectives [2]. Port performance criteria are often decisive for the competitiveness of ports, or factors influencing the competitiveness of ports [3]. Regularly measuring port productivity is crucial to finding opportunities for development and optimization [4].

According to [5] [6], their studies revealed that many ports were investing billions of dollars in port infrastructure to improve their existing facilities in order to cope with an increase in the volume of trade followed by an increase in the size of service needs. It also mentions that many ports need to enlarge their ports to meet the demand of companies and that it is challenging to develop a balance between economic, environmental and social problems to ensure growth lasting. The essence of the essential developing ports is considered to be the primary objective of all countries for which they must provide many benefits [7].

Maritime transport and the port industry now appear as indispensable vectors of development in a globalized economy, ports have played an essential economic role in the import and export processes to countries, in particular, heavy goods transport. Thus, all countries attach importance to seaports because they are the main gateway to income.

Several studies have recommended using DEA models to assess the performance and efficiency of the sector. Where to find [8], is analyzed one unit at a time. A unit is considered to work to determine the weight of their inputs and outputs. The same thing should be done for all the other units, determining the weights according to the particular optics of each. Then, if the unit is efficient, you will get the maximum rate when evaluating several other units. Some units may be considered adequate only by their criteria; others, or even have the freedom to choose weights for their inputs and outputs, can be efficient. In terms of productivity [9], study the importance of operational efficiency for hotel profitability, considered a significant target for investors, using Data Envelopment Analysis (DEA) and the return on assets. Efficiency and for the ROA, is in the 
big hotels. Highly indebted hotels have average efficiency but lower profitability than less-indebted hotels. Also, some studies have shown that the model (DEA) can be used to evaluate the services sector of public and private hospitals [10].

In this paper, the emphasis was placed on the feasibility of using the DEA model by evaluating four major ports belonging to four Indian Ocean island countries and then giving a clear view of the importance of developing inefficient ports, while [11] used DEA models to measure the efficiency of African ports. In addition to [12], evaluate ports by verifying whether or not they respond to requests. In contrast to the port performance indicators developed by UNCTAD [13], the advantage of DEA is that multiple inputs and outputs can be added to the model, and so it can provide an overall assessment of port performance [14]. There is no consensus in the selection of input and output variables [15].

\section{DEA Analysis}

The DEA is a non-parametric method of measuring the effectiveness of a decision-making unit (DMU), such as a company or a public sector Agency [16], introduced in the literature on research operations (OR) by Charnes, Cooper and Rhodes (CCR) [8]. The necessary information derived from the two DEA models, i.e. the DEA-CCR model, the DEA-BCC model is whether or not a firm can improve its performance relative to the set of firms to which it is being compared. A different set of firms is likely to provide different efficiency results because of the possible movement of the production frontier.

The DEA model (I) is mathematically expressed as [5] [6]:

(I)

$$
\max h_{k}(u, v)=\frac{\sum_{r=1}^{s} u_{r} y_{r k}}{\sum_{i=1}^{m} v_{i} x_{i k}} \text { for all } k=1,2, \cdots, n
$$

Subject to

$$
\begin{gathered}
\frac{\sum_{r=1}^{s} u_{r} y_{r j}}{\sum_{i=1}^{m} v_{i} x_{i j}} \leq 1, \quad j=1,2, \cdots, n \\
u_{r} \geq 0, \quad r=1,2, \cdots, s \\
v_{i} \geq 0, \quad I=1,2, \cdots, m
\end{gathered}
$$

where:

$h_{k}$ is relative efficiency of $k$-th DMU, $y_{r j}$ is amount of output $r$ produced by DMU $j, x_{i j}$ is amount of input $i$ used by DMU $j, n$ is the number of DMUs, $m$ is the number of inputs, $s$ is the number of outputs, $u_{r}$ is the weight given to output $r$ and $u_{i}$ is the weight given to input $i$.

The first model (I) is solved $n$ times to evaluate the relative efficiency of each DMU. Mathematically, the nonnegative constraints (3) and (4) are not sufficient for the fractional (2) to have a positive value.

For this reason, it is assumed that all the weights for inputs and outputs 
attribute a nonzero value.

Since the efficiency of the $k$-th DMU is maximized by resolving the expressions (1), (2), (3) and (4), it is evident that $h_{k}$ will take values from 0 to 1 . If the value of $\mathrm{h}_{k}$ equals 1 , the $k$-th DMU will be effective compared to the other DMU; otherwise, the value of $h_{k}$ indicates the inefficiency of the $k$-th DMU. The inefficiency of some DMU can be treated as "less effective DMU" If the value of $h_{k}$ is close to 1 .

This problem is defined as the fractional linear programming model (I), known as "CCR ratio model", which can be reduced, using transformations, to the linear programming model (II). The DEA model (II) is formulated in the following form:

(II)

$$
\max h_{k}(\mu, V)=\sum_{r=1}^{s} u_{r} y_{r k} \quad \text { for all } k=1,2, \cdots, n
$$

Subject to

$$
\begin{gathered}
\sum_{i=1}^{m} V_{i} X_{i k}=1 \\
\sum_{r=1}^{s} u_{r} y_{r k}-\sum_{i=1}^{m} V_{i} X_{i k} \leq 0, j=1,2, \cdots, n \\
\mu_{r} \geq \varepsilon, \quad r=1,2, \cdots, s \\
V_{i} \geq \varepsilon, I=1,2, \cdots, m
\end{gathered}
$$

where:

$h_{k}-$ relative efficiency of $k$-th DMU;

$n$-number of DMUs that should be compared;

$m$-number of input values;

$s$-number of output values;

$\mu_{r}$-weight of the output value $r$

$V_{i}$-weight of the input value $i$.

If the value of $h_{k}$ in the objective function is 1 , the $k$-th DMU is relatively efficient. However, if it is less than 1 , the efficiency of $\mathrm{DMU}_{k}$ is relatively low, and the value of $h_{k}$ represents the percentage of each DMU decrease its inputs. $\mathrm{DMU}_{k}$ can only be considered completely efficient if the values of other DMUs do not provide evidence that one of them is an input or output without affecting other inputs or outputs.

Looking at expressions (5), (6), (7), (8) and (9) (in model (II)) it is evident that time as a component is not incorporated.

So we can consider solutions at some point, or we can analyze the data through time series. If we ignore the time or compare the performance of some DMU to a period of time, we will use cross-sectional analysis. However, omitting other periods of time can lead to excessive use of resources and deficiencies in production in future periods. Unlike cross-sectional analysis, we can perform a time series analysis, which means that in practice, DMU is observed over several periods. Changes in the effectiveness of DMU over time can help to draw essential conclusions [17]. 
One way to use the DEA method in the time series model is the DEA window analysis. This mode is described in Charnes et al. [18]. A DMU in each period is a different DMU, and the data to be used in the analysis are panel data. The performance of a DMU is compared to its performance in other time periods and with other DMUs in the same period of time. For example, if $n$ DMUs in the model (II) in $\mathrm{N}$ time periods are considered, then a total of $\mathrm{nxN}$ DMUs must be evaluated simultaneously since DMU in year 1 is treated as a different DMU compared to the same DMU in year 2.

In many practical applications, the data available for the evaluation of DEA efficiency comes from different periods (for example, data may be monthly, quarterly, yearly, etc.). If we need to estimate the efficiency of $n$ units that have collected data on their input/output levels at any time of $\mathrm{N}$, it is possible to gather the input/output levels within a selected time frame and do only one evaluation of units n. However, this does not provide information on how the efficiency of individual units can vary over time. The changes in efficiency can be due to the evolution of staff and/or operational policy or as a result of seasonal factors that are in different units dependent in various ways. The DEA method can be used to monitor the efficiency of $\mathrm{N}$ time periods and in two ways:

- the first way each unit in each time period is considered a different unit for evaluation, which means that we should evaluate the total $n x \mathrm{~N}$ units;

- Another way is to track efficiency over time by applying window analysis. The analysis of the window consists of choosing the length of the window $p$, then evaluating the efficiencies $n \times p$ for each window (the number of Windows depends on the time interval considered). Whoever performs the analysis must determine the length of the window. An essential advantage of window analysis is that it increases the number of units for evaluation, which in turn increases the discriminatory power of the method.

\section{Data and Efficiency Analysis of Each Port}

\subsection{Variable Specification and Data}

The paper analyzes the efficiency of four ports for four Indian Ocean island countries: the port of Reunion, the port of Sri Lanka, the port of Mauritius and the port of Madagascar, as we have shown in Table 1.

The assessment of port efficiency using DEA begins with the appropriate choice of input and output variables. The total Quay length, the terminal area in

Table 1. DEA decision making units.

\begin{tabular}{ccc}
\hline S/N & Country & Ports Name \\
\hline 1 & La Reunion & Port Reunion \\
2 & Sri Lanka & Colombo Port \\
3 & Mauritius & Port Louis \\
4 & Madagascar & Port of Toamasina \\
\hline
\end{tabular}


Ha, the total numbers of cranes are chosen as input variables, while the total port cargo throughput per year is the output variable [19]. One DMU corresponds to one port.

In the process of evaluating the efficiency of the port, one of the most important inputs is the quay length. Yen-Chun Jim Wu and Mark Goh [20] suggest that quay length is crucial to the efficiency of Chinese ports. In general, quay length differs from port to port on inland waterways. River ports are smaller than seaports, and the quay length corresponds to the size of the ships that operate on the river. Since the shipping company main aim is to reduce the sum of the ships turnaround time, the optimum assignment of arrived ships to ports quay length becomes important strategy, while ports, competing for the clients (shipping companies) increase their efficiency.

The terminal area is dedicated to ending operations of receiving, storing, storing, retrieving, picking orders, packing and shipping. The field of support activities, such as the Office, is not included. Also, covered storages and open storages are included, while racks, hazardous materials and the free port area, for example, are not included. The total area determines the amount of cargo that could be transferred and stored in the port area in case of direct non-boarding or transfer of cargo outside the port area on rail/road vehicles.

The number of cranes directly influences the increase in port capacity and is therefore included in the input variables. More cranes bring greater efficiency and flexibility, allowing the port to work with more vessels simultaneously. Because port facilities are very costly, it is desirable to optimize their performance, to make better management decisions. In particular, heuristics for port operations and functional and process modelling are used to program crane loading/unloading operations to minimize the maximum time required to servicing a given set of vessels [21]. As a result, the total time that ships spend in the port is lower; the terminals are more available to other ships and the service offered to port customers improves.

The port throughput can measure the total amount of cargo that is transferred to the operational coastal zone during the year in total tons of cargo.

Table 2 lists the characteristics of the variables used to estimate the relative competitiveness of the selected port.

Table 3 lists the statistics used in the Excel DEA solver, including maximum, minimum, average, and standard deviation.

\subsection{Efficiency Analysis of Each Port}

Efficiency analysis of the proposed ports is performed using DEA window analysis. The data includes the total Quay length, terminal area in Ha, total number of cranes and port throughput per year all collected over 11 years from 2008 to 2018. The efficiencies of ports are compared over 11 years in addition to comparing them in the same period of time.

Figure 1 shows cargo throughput for selected ports from 2008-2018. 
Table 2. DEA inputs and outputs variables.

\begin{tabular}{ccc}
\hline & Variables & Measurement \\
\hline \multirow{3}{*}{ Input } & Quay length & Total quay length in meters (m) \\
& Terminal Area & The total size of the terminal in hectare (Ha) \\
Output & Quay Cranes & Total number of quay cranes \\
\hline
\end{tabular}

Table 3. Descriptive statistics for inputs and outputs variable.

\begin{tabular}{ccccc}
\hline \multirow{2}{*}{ Statistics } & \multicolumn{3}{c}{ Input } & Output \\
\cline { 2 - 5 } & Total Quay Length & Terminal Area & Number of Cranes & Cargo Throughputs \\
\hline Max & 1200 & 57 & 21 & $7,544,723$ \\
Min & 800 & 20.8 & 14 & $5,586,222$ \\
Mean & 1004 & 35.075 & 18.25 & $6,518,444.25$ \\
St.Dev. & 141.590 & 13.554 & 2.947 & $718,394.504$ \\
\hline
\end{tabular}

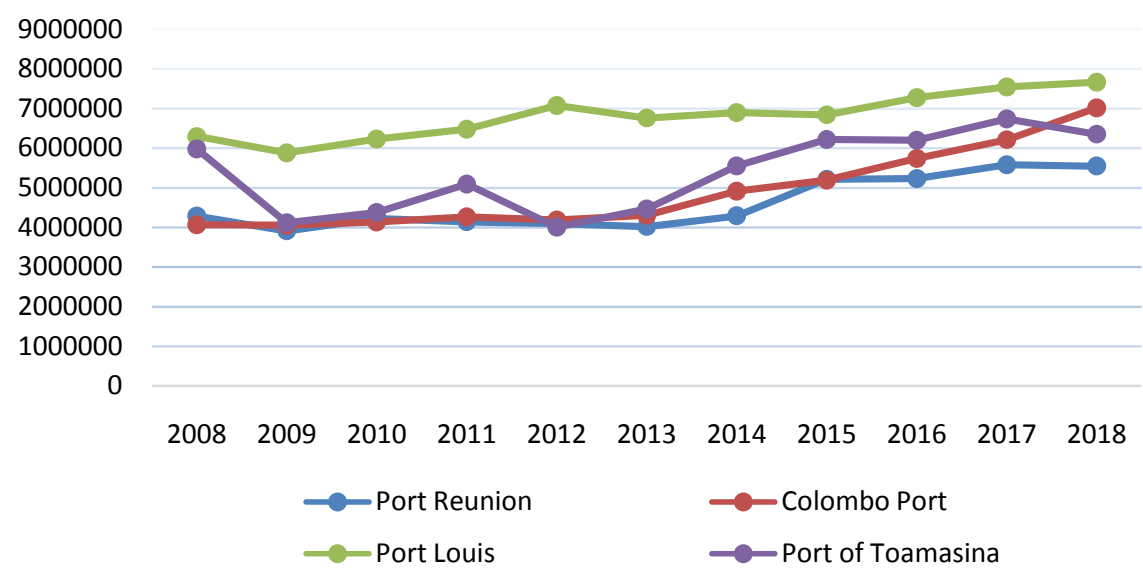

Figure 1. Cargo Throughputs (in tonnes) for 2008-2018.

We can see that Port Louis has the highest flow, and there is not so much variation; it was almost stable for all the years under study. The port of Toamasina as we have seen have so much variation in the total cargo throughput during this 11 year time study period. The Colombo Port and the port Reunion have almost the same variation, and they have an excellent performance because their total cargo throughput continues to increase during this time period of 2008-2018.

In order to monitor changes in port efficiency during the selected period or "window", the analysis of the DEA window is used. The performance of four ports over a period of eleven years is considered, then a six-year window is selected. There is no theory for defining the window length. Experiments can be performed by selecting the window of three, four or five years to determine the length of the window.

The first data set includes an analysis of the efficiency of the ports of the first six years. Similarly, the second set includes data from the second, third, fourth, 
and fifth years, and after four shifts from one year to the next, the last six sets include data from the last five years. For each window, a different data set is created. Thus, the result of different UDM per six-year period leads to differences in port efficiency, as we have shown in Figure 2 (efficiency average variation by year). This approach to efficiency analysis allows comparison of the efficiency of the port over eleven years. The results of the window analysis are solved according to the model (II).

The DEA is a commonly used tool to measure port performance and efficiency. It requires multiple inputs and outputs with accurate data and comparable DMUs. The operational efficiency of 4 main ports based on the annual cargo throughput and seeking to become the most useful port for the island countries of the Western Indian Ocean are analyzed. Panel data from 2008-2018 are employed to the DEA window analysis model to investigate the relative efficiencies over time. We used cross-sectional quantitative panel data to assess the seasonal variations in efficiency so as to prevent any misleading conclusions on port efficiency under this study. There are three input variables selected for the study, and they include the terminal area, total quay length, the total number of cranes. A single output variable, total cargo throughput, is also selected. We had chosen window six from the DEA solver result for this study, so we have a six windows table for the first six successive years. The length of the window is defined as six. Six rows per port represent six Windows. Each port is represented as a different DMU for each year. Based on the results of the model, the first of the rank was Port Louis, in terms of total quay length, the smallest one comparing to the other three ports, even though they made the extension from 2017, it remains the smallest, but they have a high throughput, which led to the conclusion that Port Louis is the most efficient port of this study with an average efficiency score of $94 \%$.

Port Reunion and Port of Toamasina are almost similar just 3\% difference of efficiency average, as we have seen in Figure 3, even though the Reunion is an

\section{Average Variation by Year}

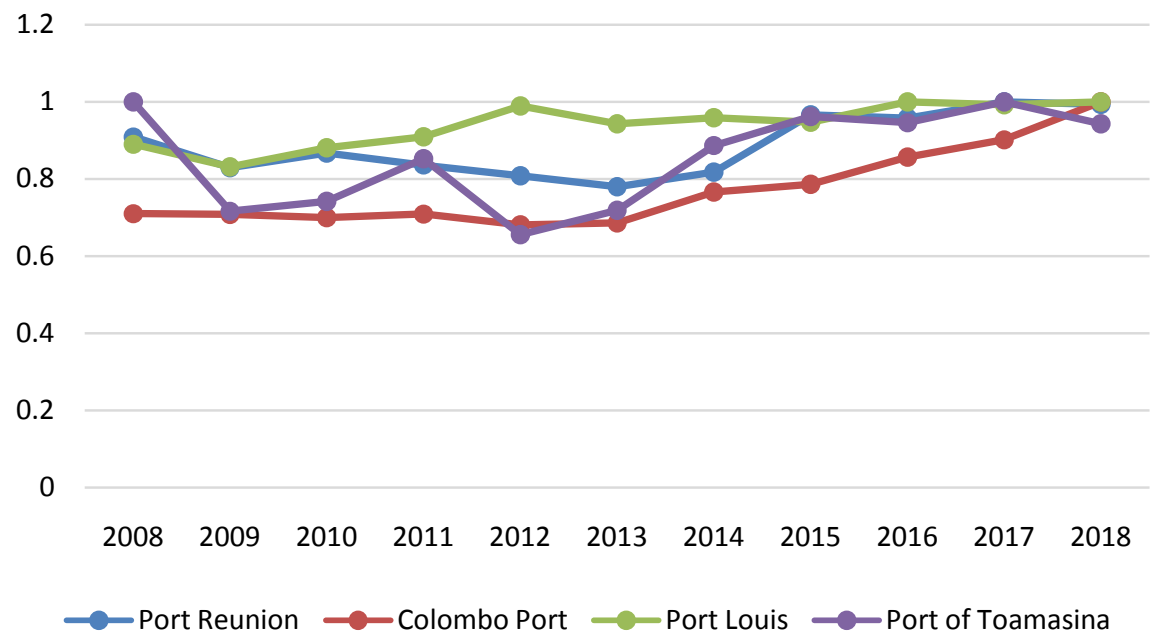

Figure 2. Efficiency average variation by year (Source: DEA solver). 


\section{Percentage of efficiency average score}

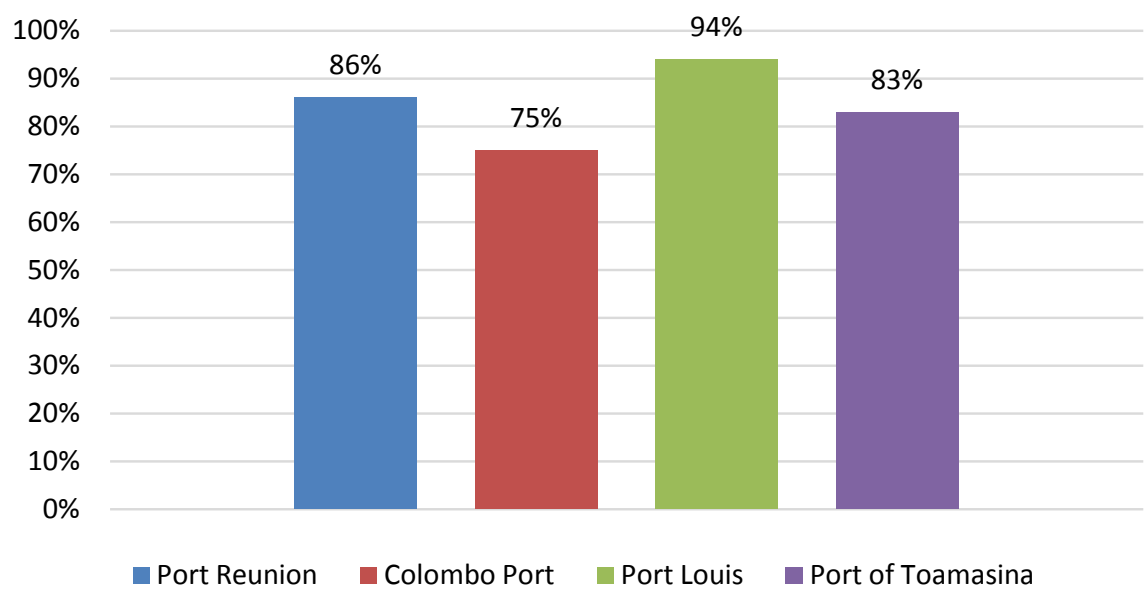

Figure 3. Percentage of efficiency average score (Source: processed by the author).

Island with the small territory of land they are more efficient compared to Madagascar, even Madagascar is a big island with a large territory. There is some extension for Port of Toamasina, the project has already started since 2015, and it will be done for 2023, the government has already started the plan and the investment for the construction. In the project, the Terminal area will be increased, the Total quay length also and the number of cranes, so maybe the total cargo throughput will increase also. Moreover, maybe the Port of Toamasina will be more efficient compared to neighbour island port in the Indian Ocean.

As we have seen, Colombo Port has low percentages of $75 \%$ efficiency average score. It is the last position of rank among the four ports. Colombo port has the most extensive surfaces in term of the terminal area, and total quay Length compares to the other three ports, but the throughput of the port is low, it can be concluded that it is the most inefficient one in Six windows of the four ports in this study.

However, if we classify these four ports according to the throughputs, in Figure 1, we see that the Port Louis is still in the first position, in the second position is the port of Toamasina, in the third position in the port of Colombo and the port of Reunion obtained the last position. Thus, we can conclude that Port Louis is the most efficient of these four ports in this study. Thus, we can learn that the high total amount of Throughputs of a port does not necessarily mean that this port is more efficient.

Those following reasons cause most sources of inefficiency, first the lack of employees trained for work in the port because almost the people who work in the port has not been learned specialization for the maritime field that is one of the problems which made the port not efficient. Second, the high level of corruption in the port, this problem affects almost those port belongs to underdeveloped countries, it is a big problem because we can find it in every sector in the port and it creates a disorder for the management in the port, and it causes the inefficiency of the port. Third, the lack of modern information and communica- 
tion technologies, most the port communication technologies are old, and there is a huge lack of information, that is one of the big inefficiency reasons because the risk of mistake is high and the information is not updated on time like the case of the port of Toamasina (Madagascar). Then, the high ports cost also is one of the reasons which make the port inefficient, because high port cost but low services quality, it makes the shipping company not interested in coming to those ports. Moreover, also the container port congestion creates a huge problem because it makes the transhipment slower and creates a delay time for the travel time of the vessel was passing by this port. Another reason that created the inefficiency of a port for underdeveloped countries west of the Indian Ocean is the high risk of political instability as the case of Madagascar in 2009, the whole system in the port was changed and create so much disorder and even the transport the company was going to leave the countries because their investments are not safe. Add to this the lack of maritime authority and the low connection of the ports to the hinterland. All these reasons make the port of the island in the west Indian Ocean inefficient.

The results obtained have valuable implications for port authorities and the government for each of the island countries in this study. Improving the efficiency of ports should be the primary objective of port authorities. It will help increase the port's performance and become the most efficient port in the western Indian Ocean. Most of the solutions to these inefficiency problems depend on the local government, and in particular the port authorities of these island countries. The government should put in place a serious investigation into the management of port authorities, which should hire the right people in the right place. Therefore, serious measures should be taken to reduce the corruption within the port, and political authorities should work harder and faster to make safe a peace life in these beautiful islands. The islands located in the Western Indian Ocean have many advantages, such as geographical location, vast land available for a future port expansion plan, financial support from private investors and cooperation from other countries such as China, Japan and the European Union. The efficiency of port performance can be measured by service quality, port throughput, seaside accessibility, landside connectivity, storage facilities and capacity, port efficiency, technology, transaction processes, cost, ships' turnaround time, and the variety of services provided. It is therefore of the view that if there is the improvement of port infrastructure, there could be a different outcome of efficiency ranking among west Indian Ocean Island Port. The measure could significantly affect the outcome of the final results of the study.

\section{Conclusion}

This study was conducted to estimate the efficiency of four ports belonging to four major islands of the western Indian Ocean for the years 2008-2018, as well as to determine their level of efficiency among them. The efficiency of these ports is determined over time by applying the DEA window analysis. The data 
used in the analysis are panel data. In order to obtain the efficiency of the port in time and its stability, the DEA method is combined with the Panel data in the window analysis model. Potential sources of inefficiencies are identified and analyzed. Proposals for future port planning and proposals for better capacity utilization in ports are formulated based on estimated efficiencies. The lack of data availability and the small sample size, which has only four ports, reveals that inputs have a significant impact on the results of the output. The input data consist of the total area of the Terminal, total quay length and number of cranes while output data include total cargo throughput per year. The results reveal that the port of Toamasina efficiency was $100 \%$ in 2008, while the Port Louis had $100 \%$ efficiency in 2016, both Port Reunion and Port of Toamsina reach 100\% efficiency also in 2017 and both Colombo port and Port Louis 100\% efficiency in 2018. This suggests that their different inputs for each port per year respond appropriately to a given output in Table 3. However, the average efficiency in all ports is less than $100 \%$. This means that all ports have more inefficiencies (port of Toamsina, port Colombo) or less (Port Louis, port reunion). There are two primary sources of inefficiencies. Firstly, it is suggesting for low-efficiency ports to attract more customers from the shipping company, to show them the advantages of the port compared to nearby ports, or to increase the amount of cargo that can be transferred by optimizing the effectiveness of the working system. Secondly, ports should lease their equipment to other companies in order to level the output (throughput) obtained with the use of inputs (total terminal area, total quay length and number of cranes). For all ports, it is essential to look at the strategic plan to improve port operations, better use of port capabilities and research tools to improve the service of these ports. Progress is being made in measuring the efficiency of ports in relation to port production activities. The lack of data availability affects the number of research analysis for the ports, as well as the number of inputs and outputs, and may obscure the real reasons for port efficiency. Thus, the research carried out here could be the beginning of a more sophisticated analysis of the port belonging to some islands of the Western Indian Ocean.

\section{Conflicts of Interest}

The author declares no conflicts of interest regarding the publication of this paper.

\section{References}

[1] Feng, M., Mangan, J. and Lalwani, C. (2013) Comparing Port Performance: Western European versus Eastern Asian Ports. International Journal of Physical Distribution and Logistics Management, 43, 490-512. https://doi.org/10.1108/09600031211246537

[2] Bonney, J. (2014) Back to Basic. Journal of Commerce, 15, 72-74.

[3] Tongzon, J. and Heng, W. (2005) Port Privatization, Efficiency and Competitiveness: Some Empirical Evidence from Container Ports (Terminals). Transportation 
Research Part A: Policy and Practice, 39, 405-424.

https://doi.org/10.1016/j.tra.2005.02.001

[4] Beskovnik, B. (2008) Measuring and increasing the Productivity of Maritime Container Terminals Intereuropa. Globalnilogističniservis, 22, 171-183.

[5] Lu, C.-S., San, K.-C. and Lin, C.-C. (2012) Identifying Crucial Sustainability Assessment Criteria for International Ports.

[6] Tukan, M., Achmadi, T. and Wijaja, S. (2012) Selection of Pilot Ports and Effect of long Dock Investment to Economic Growth with an Island. Social Sciences and Humanities Journal, 3, No. 3.

[7] Marius, A.M. and Goda (2011) Possibilities of Sustainable Development of Small Recreational Ports. Environmental Research, Engineering and Management, 58, 48-58. https://doi.org/10.5755/j01.erem.58.4.673

[8] Charnes, A., Cooper, W.W and Rhodes, E. (1978) Measuring the Efficiency of DMUs. European Journal of Operational Research, 2, 429-444.

https://doi.org/10.1016/0377-2217(78)90138-8

[9] Aisa, S.B. and Goaied, M. (2011) Determinants of Tourism Hotel Profitability in Tunisa, The Role of Managerial Efficiency. Tourism Management Journal, 52, 478-487. https://www.elsevier.com https://doi.org/10.1016/j.tourman.2015.07.015

[10] Sheih, Y., AbdulV, Reza Vahd, AliE, Saeed, D. (2012) Public and Private Hospital Services Reform Using Data Envelopment Analysis to Measure Technical, Scale, Allocative, and Cost Efficiencies. Health Promotion Perspectives, 2, 28-41.

[11] Kobina van Dyck, G. (2015) Assessment of Port Efficiency in West Africa Using Data Envelopment Analysis. American Journal of Industrial and Business Management, 5, 208-218. https://www.scirp.org/Journal/ajibm

[12] Nobrega, C. (2005) Estatistico Yearbook (2004). Director-General of ANTAQ in 2004, Brasilia, December 2005.

[13] UNCTAD (1976) Port Performance Indicators. United Nations Conference on Trade and Development, New York.

[14] Wang, T.F., Song, D.W. and Cullinane, K. (2003) Container Port Production Efficiency: A Comparative Study of DEA and FDH Approaches. Journal of the Eastern Asia Society for Transportation Studies, 5, 698-713.

[15] Tongzon, J. (2001) Efficiency Measurement of Selected Australian and Other International Ports Using Data Envelopment Analysis. Transportation Research Part A: Policy and Practice, 35, 107-122. https://doi.org/10.1016/S0965-8564(99)00049-X

[16] Ray, S.C. (2004) Data Envelopment Analysis: Theory and Techniques for Economics and Operations-Search. Cambridge University Press, London.

[17] Ramanathan, R. (2003) An Introduction To Data Envelopment Analysis: A Tool For Performance Management. Sage Publications Pvt. Ltd., New Delhi.

[18] Charnes, A., Clark, C.T., Cooper, W.W. and Golany, B. (1984) A Developmental Study of Data Envelopment Analysis in Measuring the Efficiency of Maintenance Units in the U.S. Air Forces. Annals of Operations Research, 2, 95-112. https://doi.org/10.1007/BF01874734

[19] Valentine, V.F. and Gray, R. (2001) The Measurement of Port Efficiency Using Data Envelopment Analysis. Proceedings of the 9 th World Conference on Transport Research, Seoul, 22-27 July 2001.

[20] Wu, Y.-C.J. and Goh, M. (2010) Container Port Efficiency in Emerging and More 
Advanced Markets. Transportation Research Part E, 46, 1030-1042. https://doi.org/10.1016/j.tre.2010.01.002

[21] Gudelj, A., Krčum, M. and Twrdy, E. (2010) Models and Methods for Operations in Port Container Terminals. Promet Traffic and Transportation, Scientific Journal on Traffic and Transportation Research, 22, 43-52.

https://doi.org/10.7307/ptt.v22i1.163 